\title{
Quantitative EEG Changes in Patients with Parkinson's Disease during Therapy with Rasagiline
}

\author{
Wilfried Dimpfel'1, Christian Oehlwein ${ }^{2}$, Josef Anton Hoffmann ${ }^{3}$, Thomas Müller ${ }^{4}$ \\ ${ }^{1}$ Justus-Liebig-University Giessen c/o NeuroCode AG, Wetzlar, Germany \\ ${ }^{2}$ Neurological Ambulance, Gera, Germany \\ ${ }^{3}$ TEVA Pharma GmbH, Berlin, Germany \\ ${ }^{4}$ St. Joseph-Krankenhaus, Berlin-Weissensee, Germany \\ Email: w.dimpfel@neurocode-ag.com
}

Received 20 June 2014; revised 22 July 2014; accepted 12 August 2014

Copyright (C) 2014 by authors and Scientific Research Publishing Inc.

This work is licensed under the Creative Commons Attribution International License (CC BY).

http://creativecommons.org/licenses/by/4.0/

(c) (i) 0 pen Access

\section{Abstract}

It has been suggested that in patients with Parkinson's disease (PD) metabolism of the MAO-B inhibitor selegiline to methamphetamine may contribute and/or exacerbate sleep problems, possibly leading to deficits of cognition. This open-label exploratory study included 30 PD patients currently being treated with selegiline $(7.5 \mathrm{mg} /$ day) and complaining of sleep disturbances. The aim of the study was to determine whether switching from selegiline to another MAO-B inhibitor without amphetamine-like metabolites, namely rasagiline, would improve sleep behaviour and cognitive function in PD patients. Pathologic aberrations as determined by comparison of the frequency pattern of patients to a database consisting of healthy subjects revealed an approximation of electric brain activity to normality. For verification of efficacy, a combination of questionnaires, quantitative source density EEG recording with CATEEM $^{\circledR}$ and performance of two psychometric tasks (d2-test of attention and reading) during the EEG recording were done on the last day of selegiline treatment $(7.5 \mathrm{mg} / \mathrm{day})$ as well as 2 and 4 months later, during which the patients were treated with rasagiline $(1 \mathrm{mg} /$ day). In addition, performance of the mental tasks revealed a statistically significant $(p<0.05)$ increase of theta power $(4.75-6.75 \mathrm{~Hz})$ indicative of improved cognitive abilities at the end of the treatment period. At the same time evaluation of the psychometric test results indicated a statistical improvement with respect to the score of the d2-test (increase from 6.54 to $7.37 ; \mathrm{p}<0.05$ ). Serum levels of methamphetamine were measured before and after intake of selegiline or rasagiline. They were correlated to alpha2 power, which is under dopaminergic control, within the temporal lobe. From these results it is concluded that the switch from selegiline to rasagiline not only improved sleep behaviour as reported separately but also had a positive effect on electric brain activity and on cognition in these patients. 


\section{Keywords}

\section{Rasagiline, Selegiline, Quantitative EEG, CATEEM ${ }^{\circledR}$, Parkinson's Disease, Cognition}

\section{Introduction}

It is well known that the majority of patients with Parkinson's disease (PD) suffer from daytime sleepiness and nocturnal sleep disturbances, even when their motor symptoms are optimally controlled [1]. Such sleep disturbances can have a negative impact on cognitive function, and patient quality of life. In PD, the underlying causes of sleep disturbances are complex, often resulting from the progression of the disease [2] and can also be a side effect of antiparkinsonian therapy [3]. The MAO-B inhibitor, selegiline, is metabolised to methamphetamine and amphetamine, both of which are known for causing long lasting increases in wakefulness. At the same time, methamphetamine has been shown to decrease subjective sleepiness during the night and increase subjective sleep latencies during a post-testing sleep period [4]. It is therefore hypothesized that switching from selegiline to another MAO-B inhibitor such as rasagiline [5], which does not produce amphetamine like metabolites [6], might improve sleep and cognition in Parkinson's patients. The clinical efficacy of rasagiline in PD has been established in numerous studies, both as monotherapy [7] and as adjunct to levodopa administration [8], and a recent observational study found that switching from selegiline to rasagiline resulted in significant improvements in motor and non-motor function, as well as quality of life [9]. However less is known about its effects on sleep and cognition.

The major metabolite of rasagiline, 1-(R)-aminoindan, has been shown pre-clinically to have similar effects in comparison to its parent compound with respect to EEG patterns in the rat [10]. The aim of the present study was to examine whether therapeutic switching from selegiline to rasagiline improves sleep behaviour and thereby also improves cognitive function in Parkinson's patients (this part of the study has been published [11]). The present publication deals with the results obtained by quantitative EEG analysis and was also performed to assess pathological electric activity compared to a reference database of several hundred healthy brains.

\section{Material and Methods}

\subsection{Patients}

Thirty patients ( $<75$ years old) currently treated with selegiline $(7.5 \mathrm{mg} /$ day) and with a documented history of sleep disturbance complaints were included in this study. Patients with a Hoehn \& Yahr score of $>3$, Mini Mental Score (MMSE) <24, motor fluctuations in the presence of optimized therapy or in whom rasagiline was contraindicated were excluded from the study. On day A, when patients were still taking selegiline, baseline EEG parameters were recorded, and a switch to rasagiline $1 \mathrm{mg} /$ day took place at the following day. After 2 and after 4 months of taking rasagiline the same parameters were recorded again. No placebo control was performed. Effectiveness of the switch was evaluated by comparing EEG data on day B (2 months after switch) and day C (4 months after switch) to day A (baseline, last day of previous medication with selegiline). Serum levels of methamphetamine were measured on each experimental day; this design allowed control over possible non-intended intake of selegiline during the experimental phase of rasagiline treatment. This clinical study was performed under the EudraCT \# 2008-002145-22.

\subsection{Experimental Setup}

On the first experimental day (day A), a single dose of $7.5 \mathrm{mg}$ of selegiline was administered orally after baseline recordings of EEG. Patients then underwent an overnight switch to rasagiline $1 \mathrm{mg} / \mathrm{day}$, and treatment was maintained for the next 2 months. On the second and third experimental days (days B and C), rasagiline $1 \mathrm{mg}$ was administered orally after recording of the EEG and different questionnaires [11].

\subsection{EEG Recording}

Patients (18 male/12 female) were sitting alone in a quiet separate room in a comfortable easy chair with the 
light dimmed. Baseline recording of 6 min under the condition of eyes open and 4 min with eyes closed was followed by the performance of the d2-test of attention [12] and reading an excerpt from a book by the author Ephraim Kishon. All experiments took place at the same time of the day (during the morning).

The methodology of EEG recording (CATEEM ${ }^{\circledR}$ from MEWICON CATEEM-TEC GMBH, A4164 Schwarzenberg, Austria) was reported earlier [13] [14]. In short: the raw signals were amplified, digitalized (2048 $\mathrm{Hz} / 12$ bit). The automatic artefact rejection of the CATEEM ${ }^{\circledR}$-System, which eradicates EEG-alterations caused by eye-blinks, swallowing, respiration etc. during the recording was visually controlled and individually adjusted by the investigator. Adjustment was kept constant throughout the experimental sessions. Electrooculogram (EOG) was recorded in one channel in order to facilitate detection of those signals superposing the EEG. The amount of rejected data was determined automatically and given in percent of total recording time.

In order to obtain information located in between the physically recorded locations, signals from 82 additional virtual electrodes were calculated to provide high-resolution topographical maps using a Lagrange interpolation. The signals of all 99 electrode positions (17 real and 82 virtual) underwent the Fast Fourier Transformation (FFT) based on 4-second sweeps of data epochs (Hanning window). Data were analysed from 1.25 to $35 \mathrm{~Hz}$ using the CATEEM ${ }^{\circledR}$ software, in which the resulting frequency spectra are divided into six frequency bands: delta $(1.25$ - $4.50 \mathrm{~Hz})$, theta $(4.75-6.75 \mathrm{~Hz})$, alpha1 $(7.00-9.50 \mathrm{~Hz})$, alpha2 $(9.75-12.50 \mathrm{~Hz})$, beta1 $(12.75$ - 18.50 $\mathrm{Hz})$ and beta2 $(18.75-35.00 \mathrm{~Hz})$. Colour coding of the maps is achieved by transforming the content of the power spectrum into colour pictures (i.e. 140 frequency ranges with a resolution of $0.25 \mathrm{~Hz}$ were coded into spectral colours from red to dark blue), followed by an additive mixture of the colours to give one map. Maps show the relative, time averaged changes of electrical brain activity of each recording period in $\%$ of the reference period during the corresponding recording of day A.

\subsection{Statistics}

No determination of sample size was performed for this exploratory study. Changes in $\mathrm{d} 2$ test scores between visits 1, 2 and 3 were analysed using ANOVA with a repeated measures design. The last observation carried forward method (LOCF) was used in case of missing d2 data. EEG data are not normally distributed, therefore, the non-parametric sign test was chosen for comparison between EEG results of the three experimental days among each other. Results from linear discriminant analysis according to Fischer were projected into space (x, y and $\mathrm{z}$ coordinates for the result of the first three functions) and colour (RGB mode for the result of the next three functions). To determine aberration from normality, EEG data from each individual patient (17 electrode positions $\times$ six frequency ranges giving 102 variables) were compared to a reference database consisting of 500 healthy volunteers whose EEG's were taken under identical experimental conditions [15]. After determination of the individual aberration index according to this method, all values above 1.7 (corresponding to an error probability of 50:1, which is the threshold of pathological electric activity), were summed up to give the overall aberration from normality.

\section{Results}

\subsection{Age and Concomitant Medication}

A total of 30 PD patients (18 male and 12 female; mean age $66.6 \pm 6.5$ years) currently receiving selegiline 7.5 $\mathrm{mg} /$ day and complaining about sleep problems were recruited. Motor fluctuations were well controlled in all patients by a variety of neurological medications as listed in Table 1 . The mean $( \pm S D)$ baseline Hoehn \& Yahr scorewas $2.10 \pm 0.42$, and the mean MMSE score was $28.83 \pm 1.85$. An overview on concomitant medications is given in Table 1. This medication except for Selegiline was kept constant throughout the trial.

\subsection{Overall Analysis of Regional Frequency Pattern in Comparison to Healthy Subjects}

In order to get an overall impression of the electrically defined disease state all patients were compared to our database of healthy subjects obtained during earlier clinical trials. All 102-frequency parameters (17 electrode positions times 6 frequency ranges $=102$ parameters) of each patient were matched with our database of 500 healthy volunteers (characterized under comparable experimental conditions). Differences to these normal reference values are given as the aberration index (AI), which represents the error probability with which a single value deviates from the norm database (range 1 - 4; the greater the number, the stronger the deviation). All indi- 
Table 1. Overview on additional neurological medication taken together with selegiline or rasagiline during the evaluation period of 4 months.

\begin{tabular}{cc}
\hline Neurological Medication & Number Patients \\
\hline Carbamazepine & 7 \\
Ropinirole & 22 \\
Amantadine & 12 \\
Budipine & 14 \\
Levodopa & 1 \\
Lisuride & 1 \\
Amitriptylinoxide & 11 \\
Pramipexole & 2 \\
Reboxetine & 7 \\
Cabergoline & 1 \\
Opipramol & 1 \\
Pergolide & 8 \\
Clozapine & 1 \\
Citalopram & 1 \\
Trazodone & 2 \\
Entacapone & 2 \\
Memantine & 1 \\
Rivastigmine & 3 \\
\hline
\end{tabular}

vidual deviations with an aberration index $>1.7$ corresponding to an error probability of 50:1 (threshold of pathological electric activity) were analysed. All single pathological deviations within one subject are summed up to give the overall abnormality which is given in Figure 1 for each patient as comparison between day A and day C (4 months after the switch). On day A, only 8 patients did not have pathological deviations, whereas by day C, 14 patients showed normal electric activity without pathological deviations. Values for the accumulated aberration indices decreased numerically over time after the switch to rasagiline $(\mathrm{p}<0.08)$. Similarly, the number of brain areas (electrode positions) with an error probability of $\mathrm{p}<0.02$ also decreased. Thus, this statistical disease indicator showed a clear trend to normality 4 months after switch from selegiline to rasagiline.

\subsection{Analysis of Quantitative EEG on the First Day before and after Intake of Selegiline}

Absolute electric power was determined by Fast Fourier Transformation (FFT) of the EEG data for each of the 17 electrode positions. Reference values (in $\mu \mathrm{V}^{2}$ ) from day A for the recording condition "eyes open” are given in Table 2 for both timings (baseline before drug administration and 2 hours later). No reliable recordings for 2 patients could be obtained at the second timing for technical reasons during the condition "eyes open". There were no statistically relevant differences between these values. These values are taken as reference values (100\%) for comparison to day B and day C. For the recording condition "eyes closed" absolute electric power values are given in Table 3. Due to technical problems, data from 3 patients are missing for the baseline. Values did not change during the 2 hours period in a statistically significant manner.

In order to gather information on the cognitive status of the patients, EEG recordings were also made during a mental challenge. Baseline values (in $\mu \mathrm{V}^{2}$ ) for day A are given in Table 4 for each electrode position next to values for the recording at 2 hours later during the concomitantly performed $\mathrm{d} 2$ test. Values did not change statistically during the 2-hour period. A second mental challenge consisted in the performance of reading excerpts from a book for 5 minutes. This procedure was undertaken before drug administration (baseline) and 2 hours later. Again these data were taken as reference (100\%) for comparison with day B and day C. Values did not change during the 2-hour period in a statistically significant manner. 


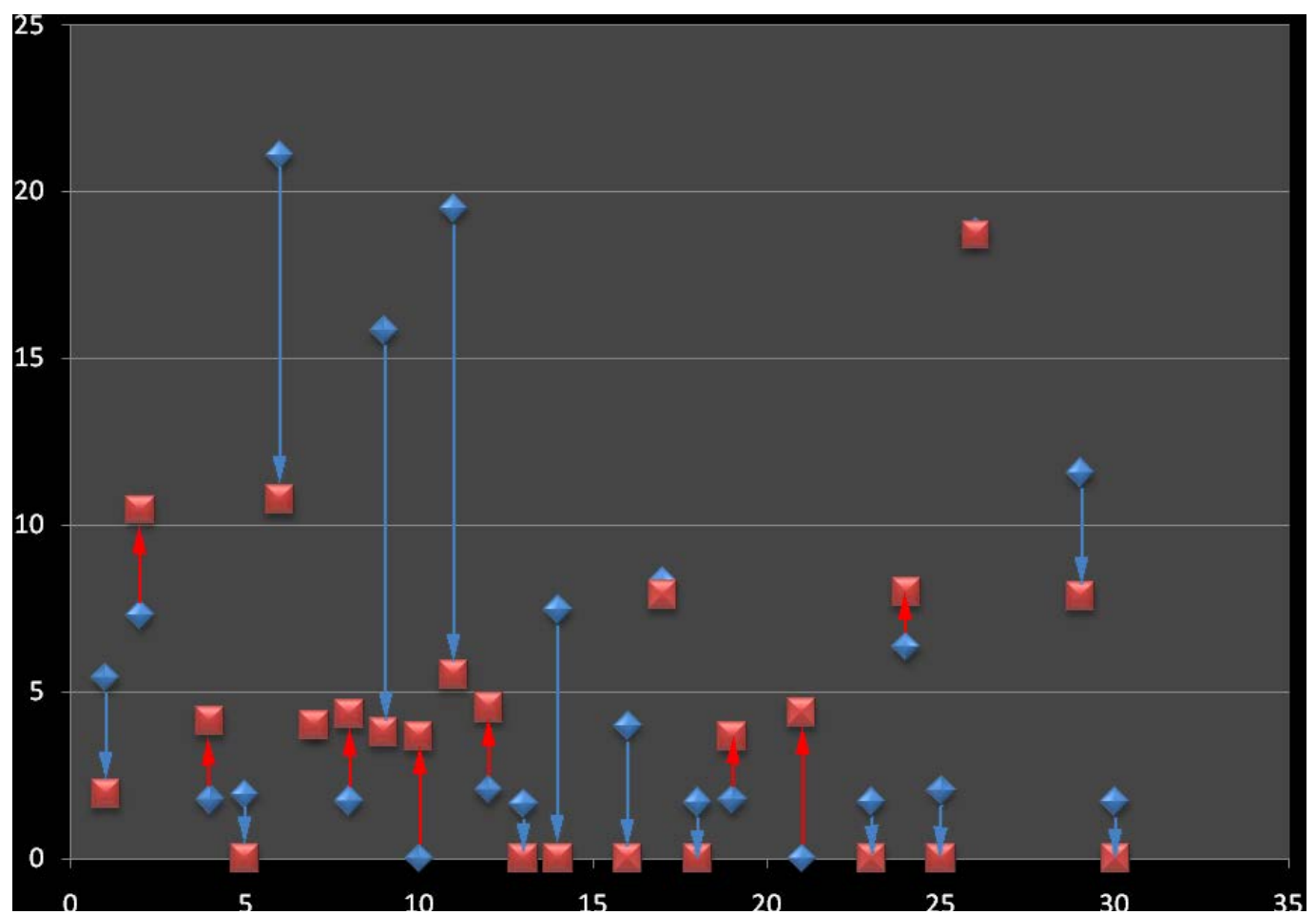

Figure 1. Individual changes of the sum of the aberration indices from all electrode positions from day A (blue dots) to day C (red dots) after treatment with rasagiline for 4 months. Changes are marked by arrows. Note that lower values indicate less pathologic aberration and that about every second patient improved.

Table 2. Absolute electric power values in $\mu \mathrm{V}^{2}$ on day A recorded at baseline before drug administration and 2 hours later during "eyes open” condition. Data represent 6 different frequency ranges from delta to beta2 waves.

\begin{tabular}{|c|c|c|c|c|c|c|c|c|c|c|c|c|c|}
\hline & & \multicolumn{2}{|c|}{ Delta } & \multicolumn{2}{|c|}{ Theta } & \multicolumn{2}{|c|}{ Alpha1 } & \multicolumn{2}{|c|}{ Alpha2 } & \multicolumn{2}{|c|}{ Beta1 } & \multicolumn{2}{|c|}{ Beta2 } \\
\hline \multicolumn{14}{|c|}{ Table of Absolute Values Eyes Open Day A } \\
\hline Electrode & Nat 0 h/Nat $2 \mathrm{~h}$ & $0 \mathrm{~h}$ & $2 \mathrm{~h}$ & $0 \mathrm{~h}$ & $2 \mathrm{~h}$ & $0 \mathrm{~h}$ & $2 \mathrm{~h}$ & $0 \mathrm{~h}$ & $2 \mathrm{~h}$ & $0 \mathrm{~h}$ & $2 \mathrm{~h}$ & $0 \mathrm{~h}$ & $2 \mathrm{~h}$ \\
\hline $\mathrm{Cz}$ & $30 / 28$ & 5.80 & 6.00 & 1.92 & 1.84 & 2.44 & 2.91 & 1.37 & 1.95 & 1.59 & 1.90 & 1.77 & 1.99 \\
\hline $\mathrm{Fz}$ & $30 / 28$ & 15.36 & 13.73 & 3.46 & 3.07 & 4.04 & 4.33 & 2.09 & 2.38 & 2.11 & 1.99 & 2.14 & 2.36 \\
\hline F3 & $30 / 28$ & 14.43 & 13.93 & 3.02 & 2.50 & 3.50 & 4.05 & 2.21 & 2.68 & 2.51 & 2.80 & 3.31 & 4.68 \\
\hline C3 & $30 / 28$ & 5.06 & 4.55 & 1.52 & 1.24 & 1.96 & 2.63 & 2.15 & 2.56 & 2.04 & 2.07 & 2.19 & 2.38 \\
\hline P3 & $30 / 28$ & 5.65 & 6.01 & 1.63 & 1.67 & 2.81 & 2.96 & 2.02 & 2.46 & 1.69 & 1.94 & 1.68 & 1.79 \\
\hline $\mathrm{Pz}$ & $30 / 28$ & 6.88 & 7.00 & 1.59 & 1.57 & 2.99 & 2.65 & 2.02 & 2.02 & 1.46 & 1.34 & 1.33 & 1.15 \\
\hline P4 & $30 / 28$ & 5.69 & 6.42 & 1.63 & 1.50 & 3.08 & 3.48 & 2.24 & 2.60 & 1.91 & 1.87 & 1.72 & 1.86 \\
\hline $\mathrm{C} 4$ & $30 / 28$ & 4.34 & 4.14 & 1.41 & 1.23 & 2.04 & 2.51 & 2.15 & 2.89 & 2.11 & 2.36 & 2.08 & 3.30 \\
\hline $\mathrm{F} 4$ & $30 / 28$ & 15.03 & 16.06 & 3.27 & 2.68 & 3.73 & 3.73 & 2.48 & 2.72 & 2.78 & 2.59 & 3.96 & 4.22 \\
\hline F7 & $30 / 28$ & 24.90 & 27.23 & 3.15 & 3.84 & 4.16 & 4.54 & 2.82 & 3.28 & 2.99 & 2.87 & 5.85 & 6.21 \\
\hline T3 & $30 / 28$ & 8.64 & 10.47 & 2.37 & 2.27 & 5.02 & 5.38 & 2.66 & 3.01 & 3.20 & 3.11 & 5.36 & 5.37 \\
\hline T5 & $30 / 28$ & 8.84 & 11.09 & 2.80 & 2.83 & 5.64 & 5.65 & 2.92 & 3.47 & 3.01 & 3.41 & 3.34 & 3.32 \\
\hline O1 & $30 / 28$ & 11.79 & 15.79 & 3.22 & 3.86 & 4.55 & 5.09 & 3.14 & 3.59 & 2.84 & 3.14 & 3.99 & 3.77 \\
\hline $\mathrm{O} 2$ & $30 / 28$ & 14.13 & 16.16 & 3.03 & 3.07 & 4.67 & 5.08 & 2.76 & 3.22 & 2.24 & 3.15 & 2.98 & 4.17 \\
\hline T6 & $30 / 28$ & 10.10 & 10.16 & 2.49 & 2.39 & 5.23 & 5.57 & 3.09 & 3.07 & 2.89 & 3.41 & 3.36 & 3.24 \\
\hline $\mathrm{T} 4$ & $30 / 28$ & 7.55 & 9.37 & 2.13 & 2.10 & 4.07 & 4.65 & 2.88 & 3.26 & 3.51 & 4.23 & 4.21 & 4.51 \\
\hline F8 & $30 / 28$ & 25.08 & 31.46 & 3.42 & 4.04 & 4.81 & 4.37 & 3.17 & 3.45 & 3.35 & 3.68 & 5.26 & 6.98 \\
\hline Median & $30 / 28$ & 9.28 & 11.43 & 2.26 & 2.51 & 3.37 & 3.86 & 2.36 & 2.94 & 2.37 & 2.63 & 2.82 & 3.09 \\
\hline
\end{tabular}


Table 3. Absolute electric power values in $\mu \mathrm{V}^{2}$ on day A recorded at baseline before drug administration and 2 hours later during “eyes closed” condition. Data represents the 6 different frequency ranges from delta to beta2 waves.

\begin{tabular}{|c|c|c|c|c|c|c|c|c|c|c|c|c|c|}
\hline & & \multicolumn{2}{|c|}{ Delta } & \multicolumn{2}{|c|}{ Theta } & \multicolumn{2}{|c|}{ Alpha1 } & \multicolumn{2}{|c|}{ Alpha2 } & \multicolumn{2}{|c|}{ Beta1 } & \multicolumn{2}{|c|}{ Beta2 } \\
\hline \multicolumn{14}{|c|}{ Table of Absolute Values Eyes Closed Day A } \\
\hline Electrode & Nat $0 \mathrm{~h} / \mathrm{Nat} 2 \mathrm{~h}$ & $0 \mathrm{~h}$ & $2 \mathrm{~h}$ & $0 \mathrm{~h}$ & $2 \mathrm{~h}$ & $0 \mathrm{~h}$ & $2 \mathrm{~h}$ & $0 \mathrm{~h}$ & $2 \mathrm{~h}$ & $0 \mathrm{~h}$ & $2 \mathrm{~h}$ & $0 \mathrm{~h}$ & $2 \mathrm{~h}$ \\
\hline $\mathrm{Cz}$ & $27 / 30$ & 6.31 & 10.57 & 2.18 & 3.21 & 3.36 & 3.64 & 1.98 & 2.37 & 1.52 & 2.04 & 2.40 & 2.21 \\
\hline $\mathrm{Fz}$ & $27 / 30$ & 12.58 & 13.78 & 3.68 & 4.10 & 5.07 & 5.45 & 2.58 & 3.27 & 2.10 & 2.06 & 2.24 & 2.33 \\
\hline F3 & $27 / 30$ & 10.56 & 12.20 & 3.06 & 3.42 & 5.18 & 4.71 & 3.05 & 3.36 & 2.48 & 2.52 & 3.12 & 2.52 \\
\hline C3 & $27 / 30$ & 6.14 & 9.45 & 1.96 & 2.34 & 4.00 & 3.59 & 2.48 & 2.55 & 2.00 & 2.11 & 2.28 & 1.97 \\
\hline P3 & $27 / 30$ & 6.81 & 9.11 & 2.04 & 2.66 & 6.87 & 4.59 & 2.34 & 2.51 & 1.49 & 1.92 & 1.85 & 1.68 \\
\hline $\mathrm{Pz}$ & 27/30 & 8.14 & 7.34 & 2.21 & 3.43 & 4.35 & 3.64 & 2.12 & 2.28 & 1.15 & 1.40 & 1.46 & 1.17 \\
\hline P4 & $27 / 30$ & 6.17 & 11.17 & 2.24 & 2.84 & 5.34 & 4.36 & 2.50 & 2.45 & 1.52 & 1.62 & 1.87 & 1.79 \\
\hline $\mathrm{C} 4$ & $27 / 30$ & 5.79 & 7.75 & 1.73 & 2.26 & 4.10 & 3.67 & 2.63 & 2.92 & 2.19 & 2.05 & 2.30 & 1.92 \\
\hline F4 & $27 / 30$ & 12.18 & 14.24 & 3.32 & 3.88 & 5.18 & 4.94 & 2.86 & 3.11 & 2.40 & 2.60 & 3.14 & 2.72 \\
\hline F7 & 27/30 & 16.53 & 17.45 & 3.12 & 3.91 & 5.71 & 5.96 & 3.10 & 3.20 & 2.52 & 2.59 & 3.27 & 2.99 \\
\hline T3 & $27 / 30$ & 9.57 & 13.58 & 3.08 & 3.51 & 5.66 & 6.73 & 2.60 & 3.25 & 2.49 & 2.51 & 3.34 & 3.64 \\
\hline $\mathrm{T} 5$ & $27 / 30$ & 10.50 & 13.30 & 4.01 & 4.59 & 8.07 & 7.47 & 3.46 & 3.54 & 3.06 & 2.75 & 2.98 & 3.14 \\
\hline O1 & $27 / 30$ & 14.44 & 17.22 & 4.03 & 5.15 & 5.61 & 6.37 & 3.77 & 3.91 & 2.88 & 2.84 & 4.01 & 3.35 \\
\hline $\mathrm{O} 2$ & $27 / 30$ & 12.82 & 18.34 & 4.14 & 4.84 & 5.39 & 6.40 & 3.37 & 3.59 & 2.49 & 2.34 & 3.43 & 2.80 \\
\hline T6 & $27 / 30$ & 9.10 & 13.40 & 3.69 & 4.38 & 7.36 & 7.11 & 2.85 & 3.55 & 2.47 & 2.67 & 2.91 & 2.97 \\
\hline $\mathrm{T} 4$ & $27 / 30$ & 11.82 & 11.81 & 3.02 & 3.79 & 6.39 & 6.73 & 3.09 & 3.25 & 3.17 & 3.08 & 4.43 & 3.63 \\
\hline F8 & $27 / 30$ & 17.33 & 18.20 & 3.61 & 4.18 & 5.75 & 5.15 & 2.97 & 3.35 & 2.57 & 3.24 & 3.39 & 3.37 \\
\hline Median & $27 / 30$ & 9.90 & 11.84 & 3.02 & 3.66 & 5.18 & 5.26 & 2.79 & 3.21 & 2.29 & 2.23 & 2.52 & 2.41 \\
\hline
\end{tabular}

Table 4. Absolute electric power values in $\mu \mathrm{V}^{2}$ on day A recorded at baseline before drug administration and 2 hours later during "performance of the $\mathrm{d} 2$ test" condition. Colouring represents the 6 different frequency ranges from delta to beta2 waves.

\begin{tabular}{|c|c|c|c|c|c|c|c|c|c|c|c|c|c|}
\hline \multicolumn{3}{|c|}{ Delta } & \multicolumn{2}{|c|}{ Theta } & \multicolumn{2}{|c|}{ Alpha1 } & \multicolumn{3}{|c|}{ Alpha2 } & \multicolumn{2}{|l|}{ Beta1 } & \multicolumn{2}{|c|}{ Beta2 } \\
\hline \multicolumn{14}{|c|}{ Table of Absolute Values d2-Test Day A } \\
\hline Electrode & $\mathrm{N}=0 \mathrm{~h} / \mathrm{N}=2 \mathrm{~h}$ & $0 \mathrm{~h}$ & $2 \mathrm{~h}$ & $0 \mathrm{~h}$ & $2 \mathrm{~h}$ & $0 \mathrm{~h}$ & $2 \mathrm{~h}$ & $0 \mathrm{~h}$ & $2 \mathrm{~h}$ & $0 \mathrm{~h}$ & $2 \mathrm{~h}$ & $0 \mathrm{~h}$ & $2 \mathrm{~h}$ \\
\hline $\mathrm{Cz}$ & $27 / 30$ & 5.82 & 6.06 & 1.82 & 1.52 & 1.60 & 1.91 & 0.82 & 1.01 & 1.12 & 1.22 & 1.64 & 1.42 \\
\hline $\mathrm{Fz}$ & $27 / 30$ & 9.17 & 8.20 & 2.67 & 2.49 & 2.45 & 2.34 & 1.35 & 1.25 & 1.62 & 1.61 & 2.12 & 2.00 \\
\hline F3 & $27 / 30$ & 10.37 & 7.81 & 2.37 & 2.37 & 2.64 & 2.48 & 1.25 & 1.40 & 1.87 & 2.21 & 3.28 & 2.93 \\
\hline C3 & $27 / 30$ & 6.88 & 4.15 & 1.47 & 1.26 & 1.67 & 1.79 & 1.10 & 1.20 & 1.46 & 1.61 & 2.24 & 1.82 \\
\hline P3 & $27 / 30$ & 5.81 & 5.34 & 1.42 & 1.35 & 1.99 & 1.74 & 1.15 & 1.40 & 1.56 & 1.61 & 1.78 & 1.49 \\
\hline $\mathrm{Pz}$ & $27 / 30$ & 5.88 & 5.37 & 1.26 & 1.40 & 1.38 & 1.47 & 0.94 & 0.96 & 0.97 & 1.08 & 1.17 & 0.96 \\
\hline P4 & $27 / 30$ & 5.40 & 5.26 & 1.15 & 1.45 & 1.59 & 1.68 & 1.16 & 1.29 & 1.68 & 1.79 & 2.31 & 2.06 \\
\hline $\mathrm{C} 4$ & $27 / 30$ & 4.35 & 4.40 & 1.27 & 1.22 & 1.52 & 1.65 & 1.16 & 1.31 & 1.64 & 1.84 & 2.08 & 1.76 \\
\hline $\mathrm{F} 4$ & $27 / 30$ & 10.27 & 10.55 & 2.60 & 2.41 & 2.94 & 2.73 & 1.45 & 1.58 & 2.07 & 2.11 & 3.73 & 3.49 \\
\hline F7 & $27 / 30$ & 16.62 & 16.19 & 3.17 & 3.35 & 5.00 & 4.41 & 2.14 & 2.61 & 2.77 & 2.68 & 4.84 & 4.22 \\
\hline T3 & $27 / 30$ & 9.90 & 8.34 & 2.41 & 2.19 & 5.11 & 4.27 & 2.34 & 3.19 & 2.90 & 2.97 & 5.70 & 5.21 \\
\hline $\mathrm{T} 5$ & $27 / 30$ & 10.06 & 8.02 & 2.85 & 2.57 & 3.69 & 3.45 & 2.58 & 2.59 & 3.67 & 3.47 & 6.25 & 4.91 \\
\hline O1 & $27 / 30$ & 12.56 & 11.53 & 4.44 & 3.33 & 5.59 & 3.68 & 2.75 & 2.68 & 3.14 & 2.84 & 4.85 & 4.47 \\
\hline $\mathrm{O} 2$ & $27 / 30$ & 11.38 & 13.27 & 3.74 & 3.63 & 4.55 & 3.72 & 2.92 & 2.80 & 4.08 & 3.33 & 7.53 & 6.04 \\
\hline $\mathrm{T} 6$ & $27 / 30$ & 6.88 & 7.32 & 2.25 & 2.25 & 3.10 & 3.55 & 2.72 & 2.96 & 3.84 & 3.65 & 5.72 & 5.14 \\
\hline $\mathrm{T} 4$ & $27 / 30$ & 9.21 & 7.54 & 2.16 & 1.96 & 3.11 & 3.73 & 2.28 & 2.99 & 3.05 & 3.34 & 5.67 & 4.75 \\
\hline F8 & $27 / 30$ & 18.16 & 18.26 & 3.77 & 3.59 & 4.18 & 4.28 & 2.18 & 2.71 & 3.06 & 3.02 & 5.58 & 4.64 \\
\hline Median & $27 / 30$ & 8.27 & 8.21 & 2.37 & 2.11 & 2.95 & 2.95 & 1.44 & 1.56 & 2.17 & 2.42 & 3.30 & 2.85 \\
\hline
\end{tabular}




\subsection{Analysis of Single EEG Variables at Day B and Day C after Administration of Rasagiline}

Comparison of the first EEG recording of the experimental day before intake of rasagiline did not reveal differences between day A and day C. However, the second recording of EEG parameters, which was performed on every experimental day at 2 hours after administration of rasagiline showed quantitative changes of spectral power.

For the recording condition "eyes open" attenuation of electric power was obvious with respect to beta1 power on day B in comparison to the same condition at day A. This attenuation was highly statistically significant in comparison to the results from day A at 8 brain regions. This change was not seen on day C, where increases of delta and theta power could be recognized, which were statistically significant at some fronto-temporal electrode positions $\left(F_{3}, T_{4}, T_{5}\right.$ and $\left.T_{6}\right)$. Results with respect to single frequency ranges and single electrode positions are depicted in Figure 2. General increase of delta and theta power in comparison to results from day A led to more red-orange colouring.

For the recording condition "eyes closed" after administration of rasagiline in comparison to the same condition at day A nearly no changes could be observed at day B except for a local decrease of alpha2 power at $\mathrm{C}_{3}$ and $\mathrm{T}_{3}$ (Figure 3). As observed for the recording condition "eyes open" increases of delta and theta power were seen on day $\mathrm{C}$ for all electrode positions except for the occipital ones (statistically significant in comparison to day A for half of the brain regions). No statistically significant differences could be recognized in comparison to the recording of day A except for an increase of delta power (which was set to $100 \%$ on day A).

During performance of the d2-test no major changes were seen when day B was compared to the data recorded on day A. But on day $\mathrm{C}$ tremendous increases of theta power could be documented during this test, which were statistically significant at $\mathrm{F}_{3}, \mathrm{~T}_{4}$ and $\mathrm{T}_{6}$ in comparison to data from day A (Figure 4).
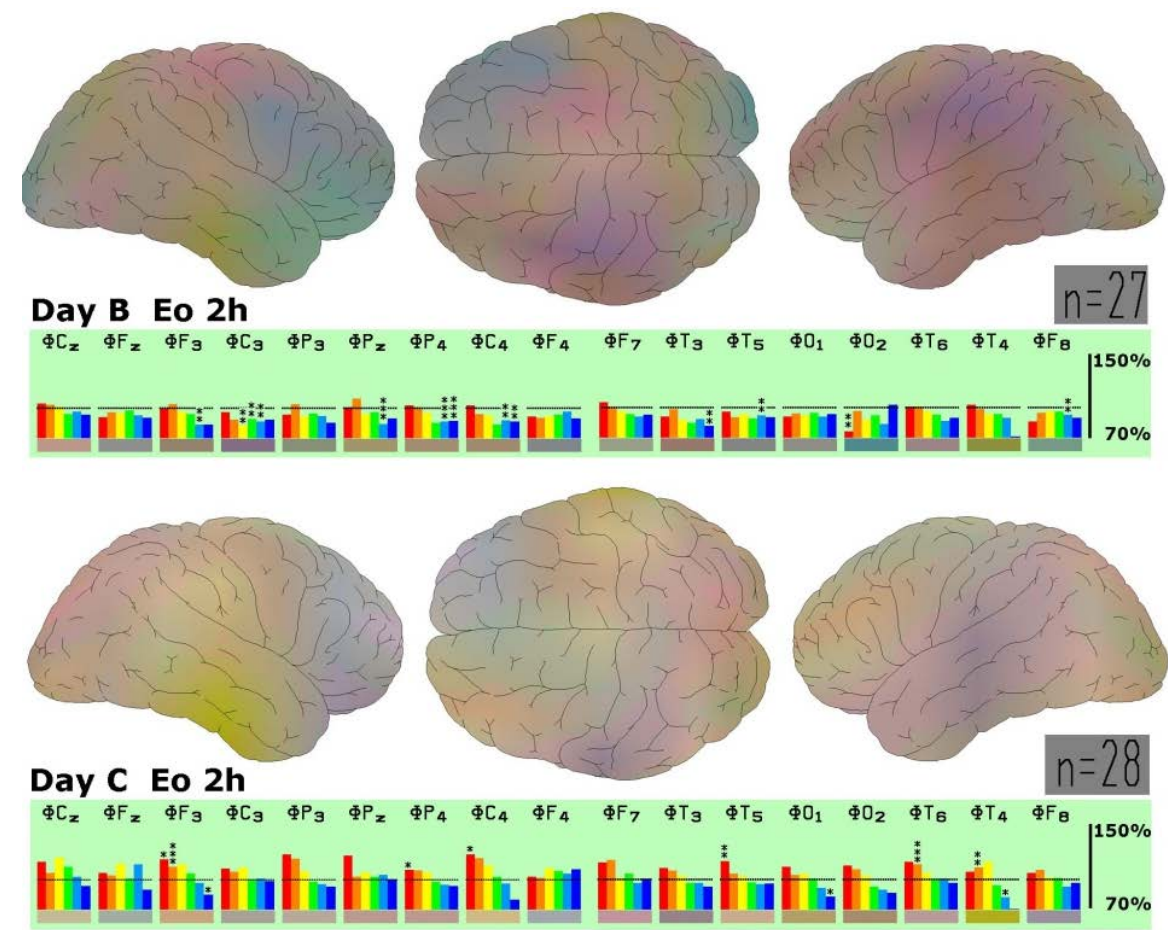

Figure 2. Recording after drug administration (2 h) on day B and day $\mathrm{C}$ under the recording condition "eyes open" (Eo). Changes of electric frequency power from day A to day B (\% of reference at day A labelled as solid line) for each frequency range and each electrode position labelled according to the $10-20$ system. $\mathrm{C}=$ central, $\mathrm{F}=$ frontal, $\mathrm{P}=$ parietal, $\mathrm{T}=$ temporal, $\mathrm{O}=$ occipital. Data are depicted for the $2^{\text {nd }}$ hour after rasagiline administration. Even numbers represent the right hemisphere, uneven numbers the left hemisphere. Frequency ranges are labelled red for delta, orange for theta, yellow for alpha1, green for alpha2, light blue for beta1 and dark blue for beta2. Asterisks represent statistical significance in comparison to day A (Selegilin administration): ${ }^{*} \mathrm{p}<0.1 ;{ }^{* *} \mathrm{p}<0.05 ;{ }^{* * *} \mathrm{p}<0.02$. 

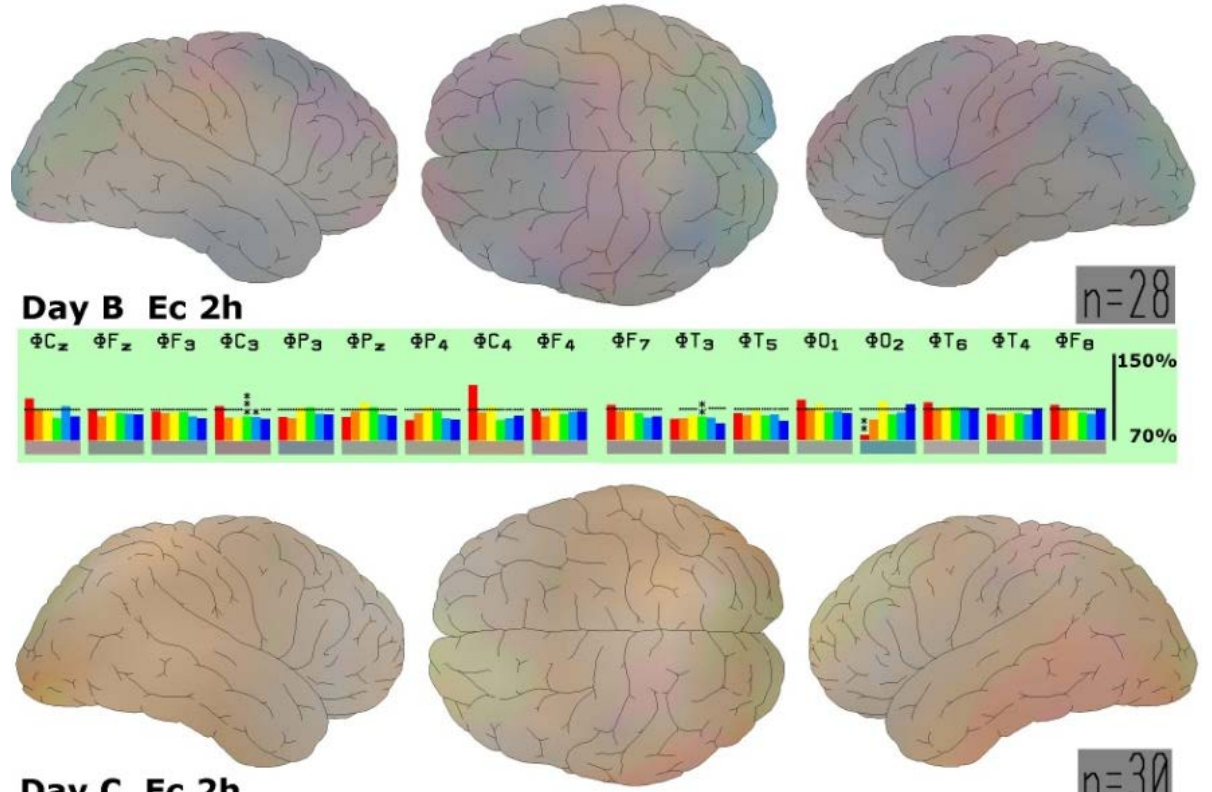

Day C Ec 2h

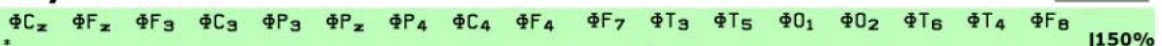

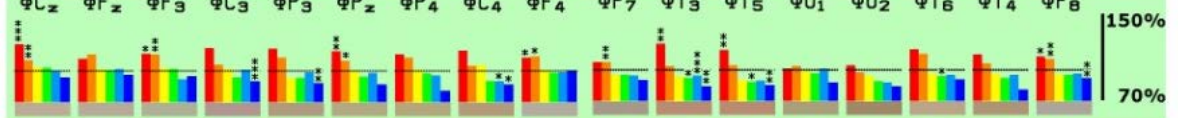

Figure 3. Recording after drug administration (2 h) on day B and day C under the recording condition "eyes closed" (Ec). For detailed description please see legend to Figure 1. Please not decrease of alpha2 waves (green) at $\mathrm{T}_{3}$ (statistically significant) and $\mathrm{T}_{4}$.
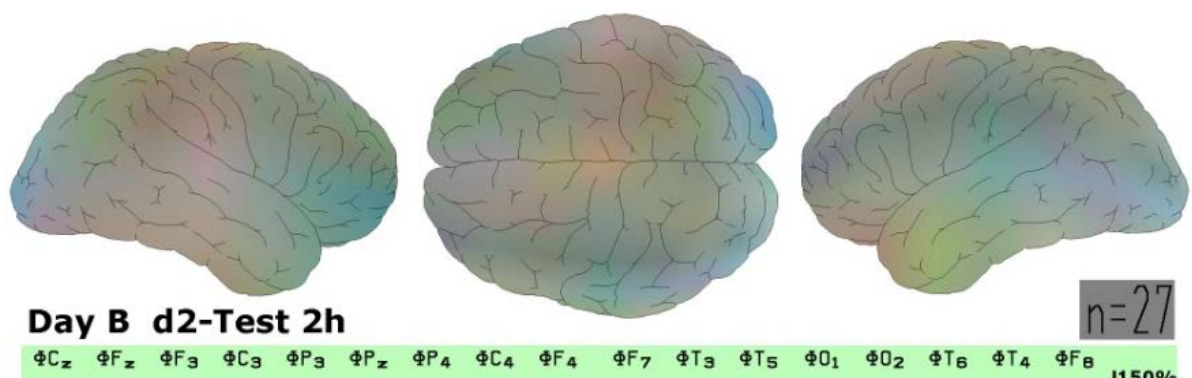

Day B d2-Test 2h

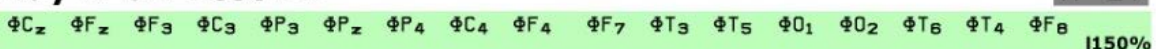
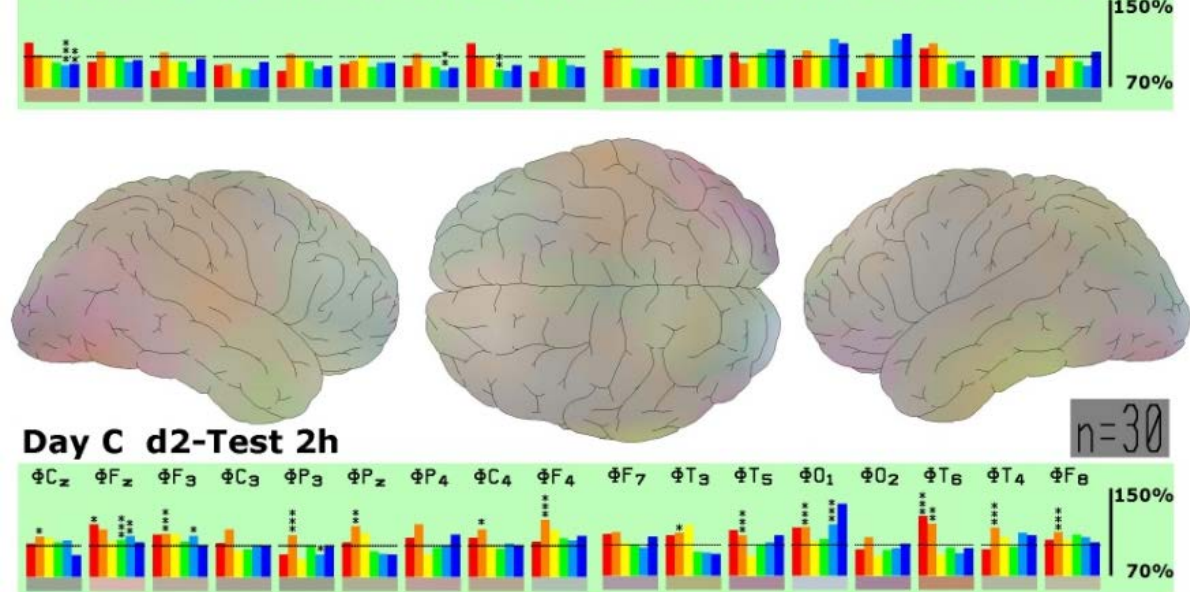

Figure 4. Recording after drug administration (2 h) on day B and day C during performance of the "d2-test" (Eo). Please note fronto-temporal and parietal increase of theta power. For detailed description please see legend to Figure 1. 
In addition to the EEG recording, psychometric performance of the patients during the d2-test was evaluated. The $\mathrm{d} 2$ performance values on day A remained below 7 at both measuring periods ( $0 \mathrm{~h}$ and $2 \mathrm{~h}$ ), whereas on day $\mathrm{B}$ and day $\mathrm{C}$ a statistically significant increase could be observed for both timings (Table 5). These values correspond well to statistically significant increases of delta and theta waves.

During performance of reading, no relevant changes were observed at day B in comparison to day A (Figure 5). However, on day $\mathrm{C}$ increases of theta power could be documented in some brain regions. At fronto-temporal regions theta power increase was seen with less than $10 \%$ error probability on day $\mathrm{C}$ in comparison to day $\mathrm{A}$.

\subsection{Discriminant Analysis}

Since calculation of mean spectral power over all electrode positions can only serve for overview of changes, more detailed information can be expected from discriminant analysis. This kind of mathematical analysis is used for detection of differences of a collective of parameters. Based on 17 electrode positions and six frequency ranges a total of 102 parameters enter discriminant analysis. The results of this approach can be depicted as projection from the poly-dimensional space. Results from the first six discriminant functions are used for construction of a six-dimensional graph (for details see section of material and methods). Under each recording condition a shift from the baseline can be seen which passes the data from day B and end in distance for the data of day C
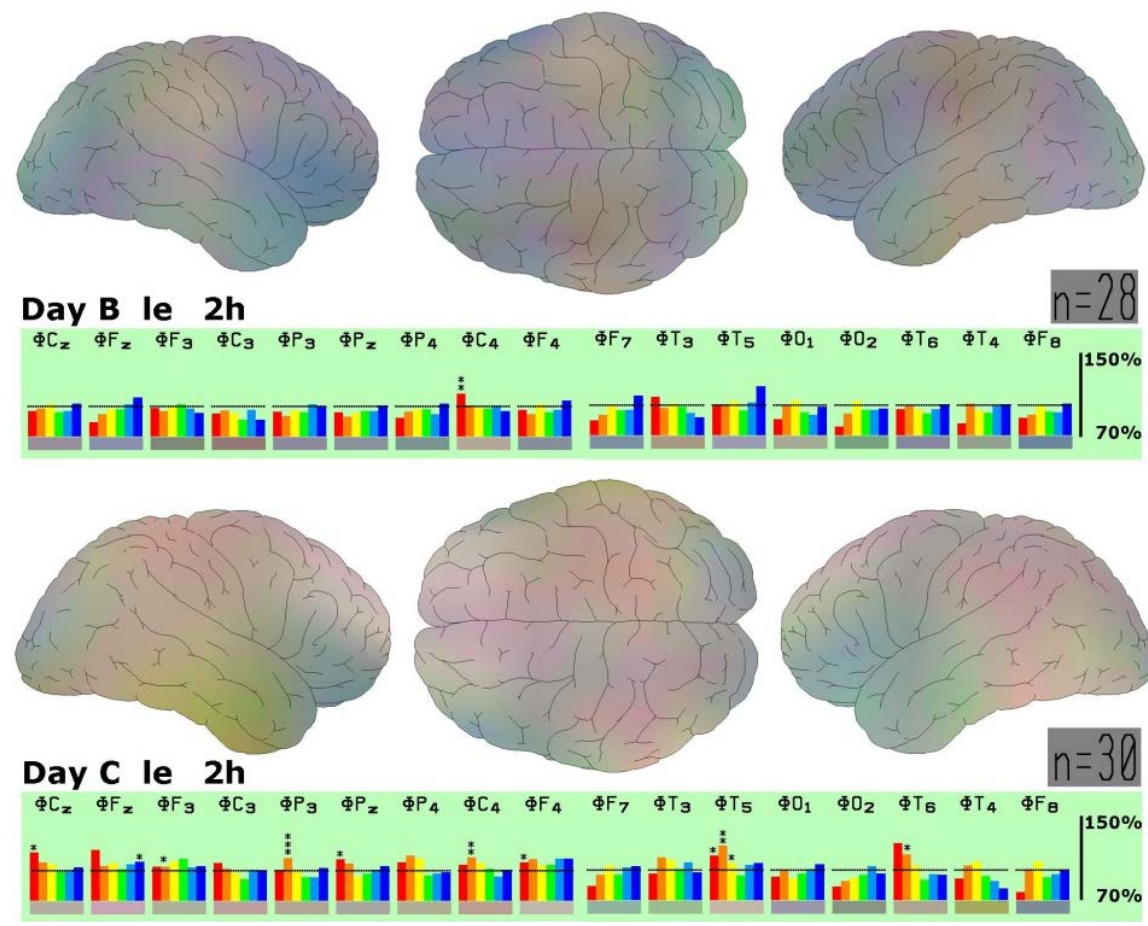

Figure 5. Recording after drug administration (2 h) on day B and day C under the recording condition "reading". Please note temporal and parietal increase of theta power. For detailed description please see legend to Figure 1.

Table 5. d2 test scores assessed during the EEG recording. Performance is given as mean and standard deviation (SD) and average error of the mean (SEM). Statistical significance is indicated by ${ }^{*}=\mathrm{p}<0.05 ;{ }^{* *}=\mathrm{p}<0.02$.

\begin{tabular}{cccccccc}
\hline & & \multicolumn{2}{c}{ Day A } & \multicolumn{2}{c}{ Day B } & \multicolumn{2}{c}{ Day C } \\
\cline { 3 - 8 } & & $0 \mathrm{~h}$ & $2 \mathrm{~h}$ & $0 \mathrm{~h}$ & $2 \mathrm{~h}$ & $0 \mathrm{~h}$ & $2 \mathrm{~h}$ \\
\hline \multirow{3}{*}{ d2-Test } & Mean & 6.54 & 6.99 & $7.47^{*}$ & $8.29^{* *}$ & $7.37^{*}$ & 7.72 \\
& SD & 2.94 & 2.95 & 2.88 & 3.05 & 3.18 & 3.90 \\
& SEM & 0.55 & 0.55 & 0.55 & 0.59 & 0.60 & 0.72 \\
\hline
\end{tabular}


(Figure 6). This can be documented for the baseline values of all days and the values recorded 2 hours later (labelled for example as "Eo" for eyes open and "A0" for baseline and "A2" for the second later recording). Thus, with respect to all recording conditions a similar shift into the same direction is observed. The electric pattern under various recording conditions definitely has changed from day A through day B up to day C.

\subsection{Plasma Level of Methamphetamine and EEG}

L-amphetamine and L-methamphetamine were only detectable in plasma during visit 1 (i.e. selegiline treatment at day A). Mean value for amphetamine increased from $0.02 \pm 0.04 \mu \mathrm{g} / \mathrm{L}$ to $0.06 \mu \mathrm{g} / \mathrm{L}$ whereas methamphetamine increased from $4.31 \pm 7.82 \mu \mathrm{g} / \mathrm{L}$ to $13.79 \pm 11.92 \mu \mathrm{g} / \mathrm{L}$ after administration of selegiline. No amphetamine or methamphetamine metabolites were detected during rasagiline treatment. Looking for a representation of metamphetamine effects in the EEG, a significant correlation between plasma level of methamphetamine and alpha2 power was detected. The result is depicted in Figure 7.

\section{Discussion}

This study included PD patients currently receiving selegiline and suffering from sleep problems. In these patients, considerable levels of methamphetamine were detected on the last day of selegiline treatment and were successfully correlated with spectral alpha2 power, which seems to be under dopaminergic control [16]. Significant changes were observed with respect to alpha2 waves under the recording condition "eyes closed" in the temporal lobe (electrode position $\mathrm{T}_{3}$ ). Thus, methamphetamine seems to lead to pathologically enhanced spectral alpha2 power and thereby to disturbances of dopaminergic neurotransmission. In patients showing such high levels of alpha2 spectral power a reduction was observed after 4 months treatment with rasagiline possibly indicating normalization of dopaminergic transmission.

In PD, cognitive disturbances are reported to go hand-in-hand with sleep problems [17], and preclinical studies in rodents indicate that methamphetamine causes serious neural and cognitive changes lasting for more than 3 weeks [18]. Replacement of selegiline with rasagiline, which is metabolized to aminoindan, was shown in this

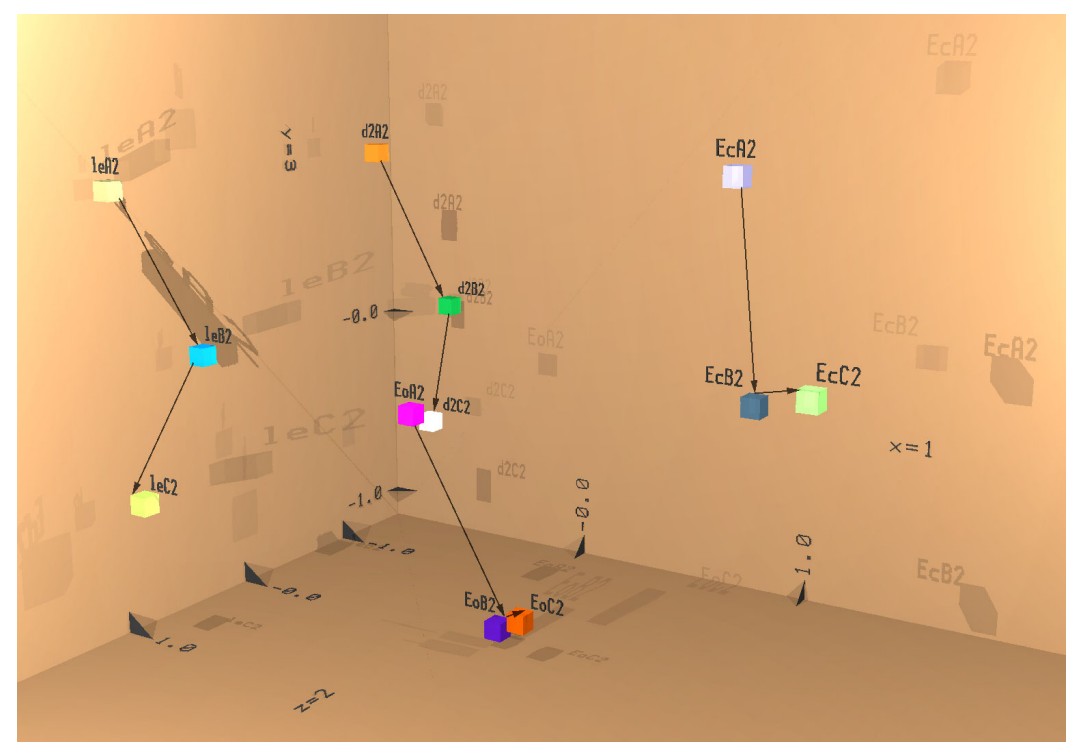

Figure 6. Result of discriminant analysis based on all 102 variables (17 electrode positions times 6 frequency ranges). Projection of the result of the first to third discriminant function was coded into space ( $\mathrm{x}, \mathrm{y}$ and $\mathrm{z}$ coordinates), of result of the fourth to sixth function into colour (RGB mode). Ec = eyes closed; Eo = eyes open; $\mathrm{d} 2$ = concentration test $\mathrm{d} 2$; le = (reading). A, B, C corresponds to recording on day A, B and C, respectively. 2 corresponds to the second recording 2 hours after drug administration. Arrows are added arbitrarily to mark changes of projection from day A through day B to day C. Please note that the data set moves from day A through day $\mathrm{B}$ to day $\mathrm{C}$ over a longer distance indicating larger changes of electric activity during the course of the disease. 


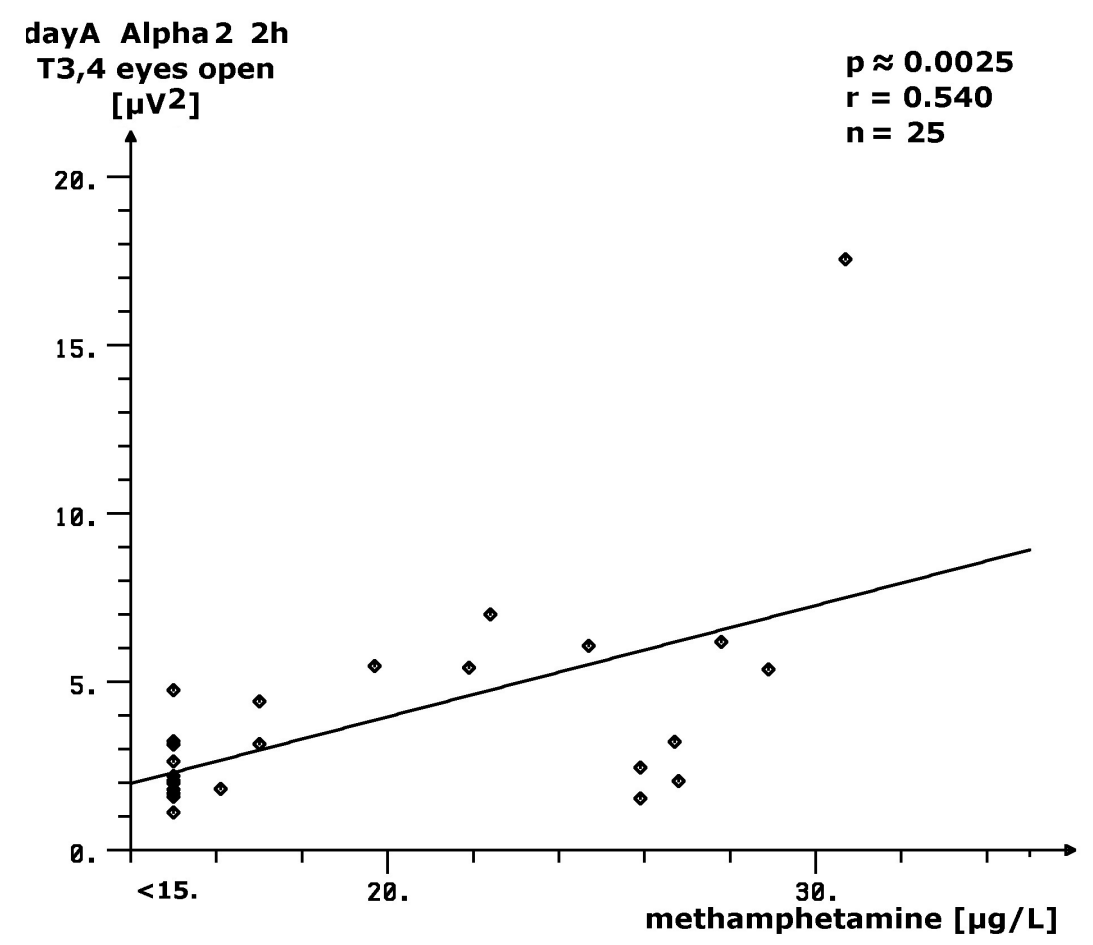

Figure 7. Spearman rank correlation and regression line between EEG frequency alpha2 spectral power at temporal electrode positions and serum methamphetamine concentrations at $2 \mathrm{~h}$ hours after intake.

study to have a positive effect on sleep [11] and cognition as assessed by quantitative EEG and psychometric testing in this report.

Whereas no frequency changes were observed between the baseline recording of the EEG on the particular experimental day and the recording 2 hours after drug intake, differences in spectral content were obvious 2 and 4 months after the switch from selegiline to rasagiline with respect to the second measurement after drug intake (day A vs. day B or day C). During these recordings, fronto-temporal theta spectral power significantly increased during performance of the d2-test and during reading. This profound increase of theta power during the d2-test is of considerable interest as fronto-temporal theta power has been shown to relate to cognitive functioning [19]-[22]. Indeed, increase of fronto-temporal theta power during performance of mental work is regarded as a surrogate parameter for better cognition. Therefore, it can be concluded that switching from selegiline to rasagiline improved mental performance of these patients. This is supported by evaluation of the psychometric performance during the concentration test, which also showed significantly better performance of the patients when on rasagiline (days B and C) versus day A when patients were on selegiline. Others have recently reported that 3-months treatment with rasagiline significantly improves attention and executive functions versus placebo in 55 non-demented PD patients as assessed by a comprehensive battery of neuropsychological tests [23]. Our results are in line with those reports, and ask for further clarification in future studies using the now available methodology of concomitant psychometric testing during quantitative EEG recording.

Using a reference database of EEG's from 500 normal people for evaluation of these changes a clear trend to less pathological features was recognized. This implies a neuroprotective capability of rasagiline since all other medications were kept constant. The cause might be seen in normalization of dopaminergic functions due to lack of amphetamine metabolism. Significant preclinical evidence now supports the potential neuroprotective properties of rasagiline and its metabolite aminoindan [24] [25]. Moreover, others [26] have recently suggested a mitochondrial site of action for rasagiline. Both rasagiline and aminoindan affect numerous mitochondrial mechanisms that prevent apoptotic cell death including prevention of opening of the mitochondrial transition pore, decreased release of cytochrome $\mathrm{C}$, alterations in pro-antiapoptotic genes and proteins, and the nuclear translocation of glyceraldehyde 3-phosphate dehydrogenase (GAPDH). As such, the functional neuroprotective actions of rasagiline may not be dependent on MAO-B inhibition, but rather may involve actions of the propargylamine 
moiety and the aminoindan metabolite on glutamatergic transmission [10].

In summary, this quantitative EEG study indicates a number of benefits of switching from selegiline to rasagiline in patients with $\mathrm{PD}$. Besides a normalization of the electric brain activity, improvement of cognitive function and resolution of sleep disturbances were documented and depressive symptomatology also seemed to improve [11].We suggest that switching from selegiline treatment of Parkinson patients to rasagiline is indicated at least when they suffer from depression, sleep disturbance and/or cognitive deficits.

\section{Acknowledgements}

We thank Mrs. Marita Oehlwein for performing the questionnaires, Mrs. Helga Kemper and Mrs. Ulrike Temme for recording the quantitative EEG's. Furthermore, we acknowledge our technicians Mrs. Petra Werling and Mrs. Leonie Schombert for processing the data and documenting the results. Mrs. Ingrid K. Keplinger-Dimpfel is acknowledged for her efforts in quality control and taking care of the logistics of the study. Last not least we thank Dr. Winfried Wedekind for guiding the study and taking care of all administrative work.

\section{Conflict of Interest}

There was no conflict of interest.

\section{References}

[1] Chaudhuri, K.R. (2002) The Basis for Day- and Night-Time Control of Symptoms of Parkinson's Disease. European Journal of Neurology, 3, 40-43. http://dx.doi.org/10.1046/j.1468-1331.9.s3.5.x

[2] Kumar, S., Bhatia, M. and Behari, M. (2002) Sleep Disorders in Parkinson's Disease. Movement Disorders, 17, 775781. http://dx.doi.org/10.1002/mds.10167

[3] Young, A., Home, M., Churchward, T., Freezer, N., Holmes, P. and Ho, M. (2002) Comparison of Sleep Disturbance in Mild versus Severe Parkinson's Disease. Sleep, 25, 573-577.

[4] Wiegmann, D.A., Stanny, R.R., McKay, D.L., Neri, D.F. and McCardie, A.H. (1996) Methamphetamine Effects on Cognitive Processing during Extended Wakefulness. The International Journal of Aviation Psychology, 6, 379-397. http://dx.doi.org/10.1207/s15327108ijap0604_5

[5] Thébault, J.J., Guillaume, M. and Levy, R. (2004) Tolerability, Safety, Pharmacodynamics, and Pharmacokinetics of Rasagiline: A Potent, Selective, and Irreversible Monoamine Oxydase Type B Inhibitor. Pharmacotherapy, 24, 12951305. http://dx.doi.org/10.1592/phco.24.14.1295.43156

[6] Finberg, J.P., Lamensdorf, I., Commissiong, W. and Youdim, M.B. (1996) Pharmacology and Neuroprotective Properties of Rasagiline. Journal of Neural Transmission. Supplementa, 48, 95-101.

[7] Stern, M.B., Marek, K.L., Friedmann, J., Hauser, R.A., LeWitt, P.A., Tarsy, D. and Olanow, C.W. (2001) Double Blind, Randomized, Controlled Trial of Rasagiline as Monotherapy in Early Parkinson's Disease Patients. Movement Disorders, 19, 916-923. http://dx.doi.org/10.1002/mds.20145

[8] Rabey, J.M., Sagi, L., Huberman, M., Melamed, E., Korczyn, A., Giladi, N., Inzelberg, R., Djaldetti, R., Klein, C. and Berecz, G. (2000) Rasagiline Mesylate: A New MAO B Inhibitor for the Treatment of Parkinson’s Disease: A Double Blind Study as Adjunctive Therapy to Levodopa. Clinical Neuropharmacology, 23, 324-330. http://dx.doi.org/10.1097/00002826-200011000-00005

[9] Reichmann, H. and Jost, W.H. (2010) Efficacy and Tolerability of Rasagiline in Daily Clinical Use-A Post-Marketing Observational Study in Patients with Parkinson's Disease. European Journal of Neurology, 17, 1164-1171. http://dx.doi.org/10.1111/j.1468-1331.2010.02986.x

[10] Dimpfel, W. and Hoffmann, J.A. (2010) Electropharmacograms of Rasagiline, Its Metabolite Aminoindan and Selegiline in the Freely Moving Rat. Neuropsychobiology, 62, 213-220. http://dx.doi.org/10.1159/000319947

[11] Müller, T., Hoffmann, J.A., Dimpfel, W. and Oehlwein, C. (2013) Switch from Selegiline to Rasagiline Is Beneficial in Patients with Parkinson's Disease. Journal of Neural Transmission, 120, 315-318. http://dx.doi.org/10.1007/s00702-012-0927-3

[12] Ziegler, E. and Rambach, H. (1978) Development of Standard Psychological Values for Measuring Brain Performance at Different Ages under Normal and Pathological Aspects. Zentralstelle für das Auslandsschulwesen, 33, 413-419.

[13] Dimpfel, W., Kler, A., Kriesl, E., Lehnfeld, R. and Keplinger-Dimpfel, I.K. (2006) Neurophysiological Characterization of a Functionally Active Drink Containing Extracts of Ginkgo and Ginseng by Source Density Analysis of the Human EEG. Nutritional Neuroscience, 9, 213-224. http://dx.doi.org/10.1080/10284150601043713 
[14] Dimpfel, W., Koch, K. and Weiss, G. (2011) Early Effect of NEURAPAS ${ }^{\circledR}$ Balance on Current Source Density (CSD) of Human EEG. BMC Psychiatry, 11, 123. http://dx.doi.org/10.1186/1471-244X-11-123

[15] Vonderheid-Guth, B., Todorova, A., Wedekind, W. and Dimpfel, W. (2000) Evidence for Neuronal Dysfunction in Migraine: Concurrence between Specific qEEG Findings and Clinical Drug Response-A Retrospective Analysis. European Journal of Medical Research, 5, 473-483.

[16] Dimpfel, W. (2008) Pharmacological Modulation of Dopaminergic Brain Activity and Its Reflection in Spectral Frequencies of the Rat Electropharmacogram. Neuropsychobiology, 58, 178-186.

[17] Johnson, A.L., Brown, K. and Weaver, M.T. (2010) Sleep Deprivation and Psychomotor Performance among NightShift Nurses. AAOHN Journal, 58, 147-154.

[18] Marshall, J.F., Belcher, A.M., Feinstein, E.M. and O’Dell, S.J. (2007) Methamphetamine-Induced Neural and Cognitive Changes in Rodents. Addiction, 102, 61-69. http://dx.doi.org/10.1111/j.1360-0443.2006.01780.x

[19] Schober, F., Schellenberg, R. and Dimpfel, W. (1995) Reflection of Mental Exercise in the Dynamic Quantitative Topographical EEG. Neuropsychobiology, 31, 98-112. http://dx.doi.org/10.1159/000119179

[20] Jelic, V., Johansson, S.E., Almkvist, O., Shigeta, M., Julin, P., Nordberg, A., Winblad, B. and Wahlund, L.O. (2000) Quantitative Electroencephalography in Mild Cognitive Impairment: Longitudinal Changes and Possible Prediction of Alzheimer's Disease. Neurobiology of Aging, 21, 533-540. http://dx.doi.org/10.1016/S0197-4580(00)00153-6

[21] Alexander, D.M., Arns, M.W., Paul, R.H., Rowe, D.L., Cooper, N., Esser, A.H. and Fallahpour, K. (2006) EEG Markers for Cognitive Decline in Elderly Subjects with Subjective Memory Complaints. Journal of Integrative Neuroscience, 5, 49-74. http://dx.doi.org/10.1142/S0219635206001021

[22] Prichep, L.S., John, E.R., Ferris, S.H., Rausch, L., Fang, Z., Cancro, R., Torossian, C. and Reisberg, B. (2006) Prediction of Longitudinal Cognitive Decline in Normal Elderly with Subjective Complaints Using Electrophysiological Imaging. Neurobiology of Aging, 27, 471-481. http://dx.doi.org/10.1002/mds.23738

[23] Hanagasi, H.A., Gurvit, H., Unsalan, P., Horozoglu, H., Tuncer, N., Feyzioglu, A., Gunal, D.I., Yener, G.G., Cakmur, R., Sahin, H.A. and Emre, M. (2011) The Effects of Rasagiline on Cognitive Deficits in Parkinson's Disease Patients without Dementia: A Randomized, Double-Blind, Placebo-Controlled, Multicenter Study. Movement Disorders, 26, 1851-1858. http://dx.doi.org/10.1002/mds.23738

[24] Naoi, M. and Maruyama, W. (2009) Functional Mechanism of Neuroprotection by Inhibitors of Type B Monoamine Oxidase in Parkinson's Disease. Movement Disorders, 9, 1233-1250. http://dx.doi.org/10.1586/ern.09.68

[25] Bar-Am, O., Weinreb, O., Amit, T. and Youdim, M.B. (2010) The Neuroprotective Mechanism of 1-(R)-Aminoindan, the Major Metabolite of the Anti-Parkinsonian Drug Rasagiline. Journal of Neurochemistry, 112, 1131-1137. http://dx.doi.org/10.1111/j.1471-4159.2009.06542.x

[26] Jenner, P. and Langston, J.W. (2011) Explaining ADAGIO: A Critical Review of the Biological Basis for the Clinical Effects of Rasagiline. Movement Disorders, 26, 2316-2323. http://dx.doi.org/10.1002/mds.23926 
Scientific Research Publishing (SCIRP) is one of the largest Open Access journal publishers. It is currently publishing more than 200 open access, online, peer-reviewed journals covering a wide range of academic disciplines. SCIRP serves the worldwide academic communities and contributes to the progress and application of science with its publication.

Other selected journals from SCIRP are listed as below. Submit your manuscript to us via either submit@scirp.org or Online Submission Portal.
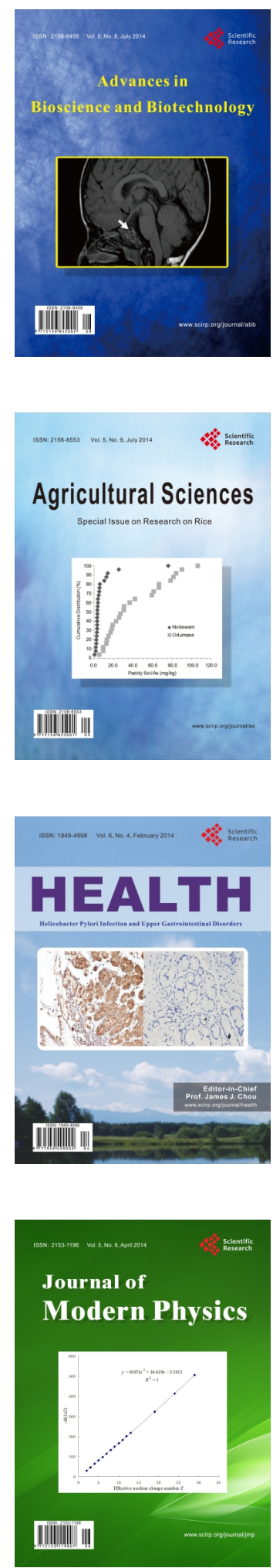
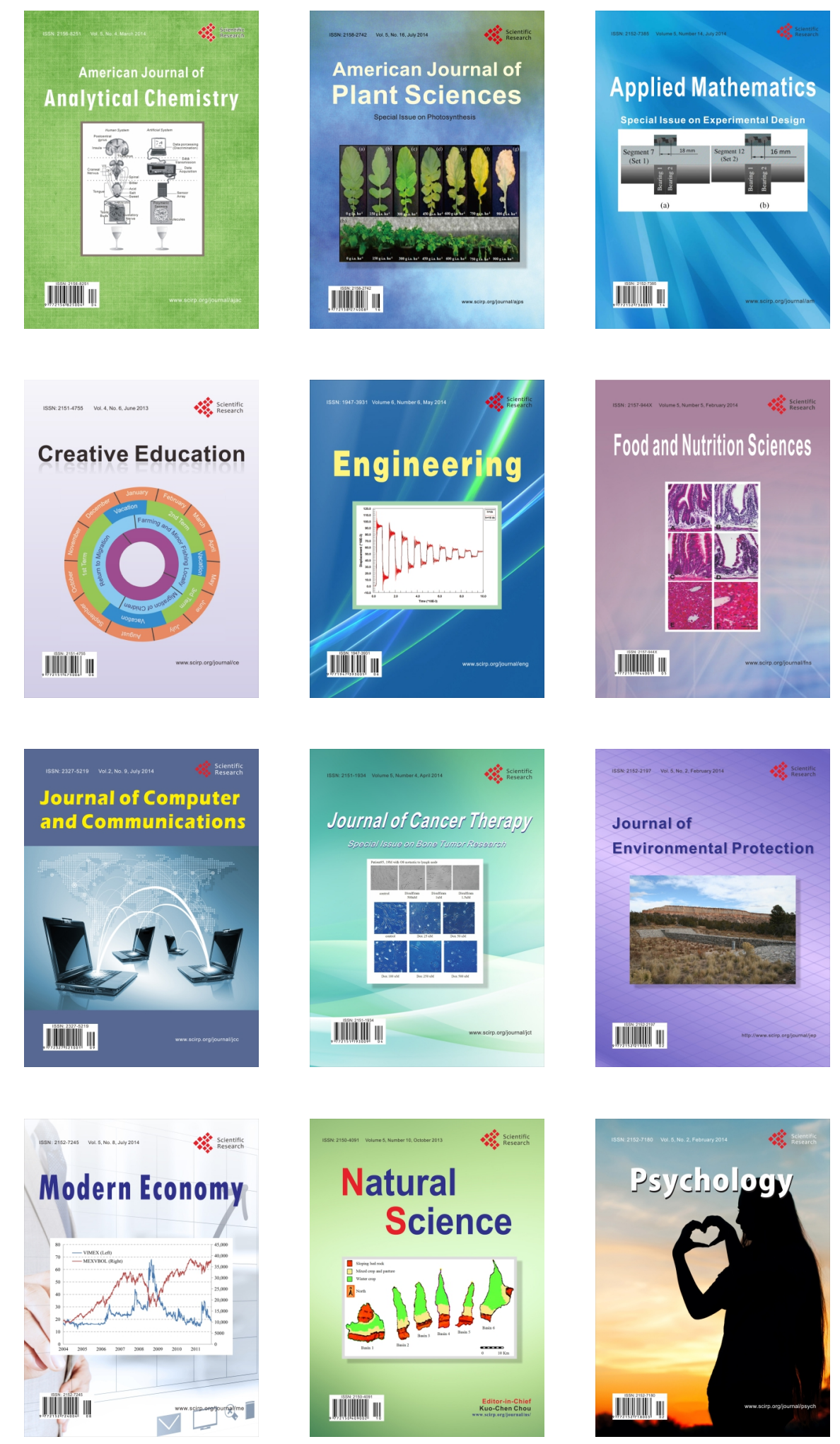